\title{
A genetic study of von Recklinghausen neurofibromatosis in south east Wales. II Guidelines for genetic counselling
}

\author{
S M HUSON*, D A S COMPSTON†, AND P S HARPER* \\ From the Institute of Medical Genetics* and Section of Neurologyt, University of Wales College of Medicine, \\ Heath Park, Cardiff CF4 4XN
}

SUMmARY The age of appearance and diagnostic value of the major defining features of von Recklinghausen neurofibromatosis (NF-1) have been studied in 168 cases from 73 families. In assessing children of an affected patient, those who have inherited the gene can be distinguished from their normal sibs on the basis of whether or not café au lait (CAL) spots are present by the age of five years. Lisch nodules appear before cutaneous neurofibromas and are a useful clinical aid in the assessment of unusual cases, those in whom the diagnosis is equivocal, and children with multiple CAL spots but no family history of NF-1. Sixty-nine of the families were identified through a population based study in south east Wales and the frequency of complications in 135 affected subjects from these families has been used to develop figures for genetic counselling. For these purposes, the complications of NF-1 can be usefully divided into four categories: intellectual handicap $(33 \%)$ (moderate/severe retardation $3.2 \%$, minimal retardation/learning difficulties $29.8 \%$ ); complications developing in childhood and causing lifelong morbidity $(8.5 \%)$; 'treatable' complications which can develop at any age (15.7\%); and malignant or CNS tumours $(4 \cdot 4$ to $5 \cdot 2 \%)$.

The recent mapping of the gene for NF-1 to chromosome $17,{ }^{2}$ subsequent exclusion of possible heterogeneity, and rapid development of closely linked polymorphic DNA markers ${ }^{3}$ means that prenatal/presymptomatic diagnosis for this disease is now possible with $>95 \%$ accuracy in families with a suitable structure. But in a disorder showing such varied expression and complications the decision to have prenatal diagnosis is far from clear cut and the onus is upon genetic counsellors to provide accurate information regarding the incidence of disease complications and long term prognosis for disease sufferers. Prenatal diagnosis will not be an option in the immediate future for approximately $50 \%$ of cases $^{45}$ who represent new mutations at the NF-1 locus. Yet in counselling these cases and their parents similar information is needed; the parents of children who are new mutations are often referred for counselling when the child is young and when reassured about the recurrence risks for their future offspring, a principal concern is to learn about their child's future.

Received for publication 15 November 1988. Accepted for publication 7 February 1989.
On reviewing published reports on neurofibromatosis several problems arise in the interpretation of data available for counselling purposes. In some studies no clear distinction has been made between NF-1 and other forms of neurofibromatosis,,${ }^{467}$ and in others, as the study sample is not population based,,$^{8-10}$ the incidence of complications may be an overestimate resulting from referral of more severely affected cases for specialist assessment. Table 1 highlights this problem by summarising the incidence of selected complications of NF-1 in the four largest previous studies. ${ }^{4689}$ No study has looked specifically at the age of onset of the major defining features of the disease (CAL spots, peripheral neurofibromas, and Lisch nodules) to derive an age when relatives at risk, not showing these features, can be reassured that they do not carry the gene.

Between October 1983 and February 1986 a population study of NF-1 was undertaken in south east Wales. The clinical findings and genetic analysis have been described elsewhere. ${ }^{511}$ In this report we look at the outcome with particular reference to genetic counselling aiming to determine the age at which the gene can be excluded in at risk relatives 
with no disease features, and the frequency and age at presentation of disease complications.

\section{Materials and methods}

The methods of case ascertainment, clinical assessment, and diagnostic criteria used are described in the preceding paper. ${ }^{5}$ For the analysis of age of onset of major defining features, data on relatives of the families living outside the study area (who were examined for the purpose of linkage studies), and from four families ascertained through the patients' association LINK used in linkage studies, ${ }^{12}$ have been added. All these subjects underwent the same assessment protocol as those living in the study area.

The frequency of complications is derived solely from the population based study except for CNS tumours and other malignancies associated with NF-1. These were derived from the frequency in all index cases and affected relatives aged $\geqslant 18$ years on 1 June 1985 within and outside the study area and in dead affected relatives in whom the diagnosis was certain.

\section{Results}

The family resource is summarised in fig 1 . Although 168 affected subjects were potentially available for assessing the major defining features, examination was either not performed or was inadequate in 13 subjects. A portable slit lamp was only available for part of the study and the Lisch nodule data are therefore less complete.

\section{MAJOR DEFINING FEATURES}

Two approaches have been used to look at the frequency of each of the three defining features of

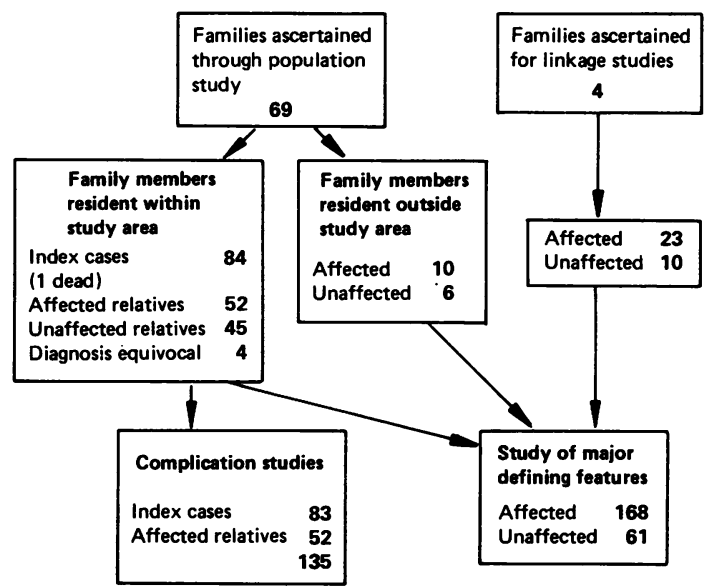

FIG 1 Ascertainment of NF-1 families and outcome of clinical assessment. Only affected subjects living in the south east Wales study area have been used in the analysis of complications. Relatives of index cases who had one to five $C A L$ spots, no other features, and were under five years old (three subjects) and those over five years with three to five $C A L$ spots (one subject, aged six years) were classified as equivocal.

NF-1. Table 2 shows the percentage by age of affected subjects who had each diagnostic feature. In fig 2 children of affected subjects, in families where the index case was an adult, have been analysed to see at what age, taking each feature in isolation, the expected $1: 1$ segregation ratio for a dominant disorder is reached.

CAL SPOTS

CAL spots were the first disease feature to appear in

TABLE 1 Prevalence of selected disease complications in the four previous largest studies of NF-1.

\begin{tabular}{|c|c|c|c|c|}
\hline & Crowe et at & $\begin{array}{l}\text { Brasfield and } \\
\text { Das Gupta }\end{array}$ & Carey et al & Riccardi and Eichner ${ }^{9}$ \\
\hline Ascertainment of cases & $\begin{array}{l}\text { Hospital records } \\
\text { family studies }\end{array}$ & Hospital records & $\begin{array}{l}\text { Genetic clinic } \\
\text { records }\end{array}$ & $\begin{array}{l}\text { Cases referred to } \\
\text { special interest clinic }\end{array}$ \\
\hline No of cases & 223 & 110 & 131 & 238 \\
\hline $\begin{array}{l}\text { Other forms of } \\
\text { neurofibromatosis excluded }\end{array}$ & No & $\begin{array}{l}\text { Diagnostic criteria } \\
\text { not stated }\end{array}$ & No & Yes \\
\hline \multicolumn{5}{|l|}{ Prevalence of complication ( $\%)$} \\
\hline IQ $<70$ & NS* & NS & 10 & 8 \\
\hline CNS tumours & 3 & 8 & $7 \div$ & $15 \div$ \\
\hline Acoustic neuroma & 5 & 0 & NS & () \\
\hline Peripheral nerve malignancy & 2 & 29 & 0 & 4 \\
\hline Scoliosis (all forms) & 7 & NS & 5 & 29 \\
\hline
\end{tabular}

${ }^{*} \mathrm{NS}=$ not specified

†Series probably includes one case with bilateral acoustic neurofibromatosis (NF-2).

†All optic gliomas: $10 \%$ asymptomatic. diagnosed by $\mathrm{CT}$. 
TABLE 2 Change in frequency of the major defining features of NF-1 with age.

\begin{tabular}{|c|c|c|c|c|c|c|}
\hline \multirow[t]{2}{*}{$\begin{array}{l}\text { Age } \\
\text { (No of cases) }\end{array}$} & \multicolumn{2}{|c|}{$\begin{array}{l}\text { CAL spots* } \\
(n=155)\end{array}$} & \multicolumn{3}{|c|}{$\begin{array}{l}\text { Cutaneous neurofibromas } \\
(n=155)\end{array}$} & \multirow{2}{*}{$\begin{array}{l}\text { Lisch nodules } \\
(n=122)\end{array}$} \\
\hline & $\begin{array}{l}\text { Min-max } \\
\text { No }\end{array}$ & $\begin{array}{l}\% \text { of cases } \\
\text { with } \geqslant 6\end{array}$ & $\begin{array}{l}\% \text { of } \\
1-10\end{array}$ & $11-110$ & $>100$ & \\
\hline $0-10(21)$ & $8-27$ & $1(x)$ & 10 & 0 & 0 & 79 \\
\hline $11-20(35)$ & $5-30$ & 97 & 40 & 14 & 3 & 85 \\
\hline $21-30(28)$ & $5-17$ & 93 & 25 & 57 & 18 & 90 \\
\hline $41-50(13)$ & $3-16$ & 62 & 0 & 15 & 85 & 88 \\
\hline $51-60(13)$ & $2-16$ & 77 & 0 & 46 & 64 & 10() \\
\hline$\cdot 61-70(13)$ & ()-13 & 62 & 0 & 0 & 100 & 88 \\
\hline $71-85 \quad(6)$ & $2-5$ & 0 & 0 & 17 & 83 & 100 \\
\hline
\end{tabular}

${ }^{*}$ A diameter of $>0.5 \mathrm{~cm}$ was used in counting CAL spots in cases aged $\leqslant 14$ years and $1.5 \mathrm{~cm}$ for those $>14$ years.
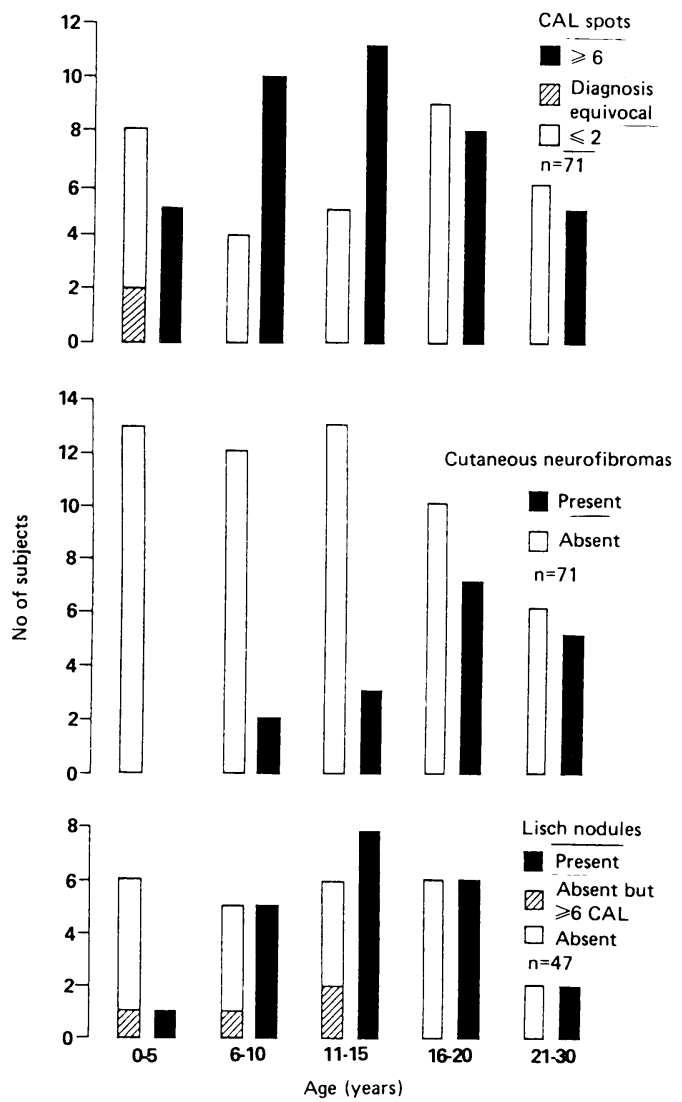

FIG 2 Presencelabsence of major defining features in the offspring of affected subjects analysed by age; families in which the only index case was a child have been excluded.

all cases and the data in fig 2 indicate that affected and unaffected subjects can be distinguished on this criterion alone by five years. Parents had noted CAL spots for the first time at four years or less in all affected children and within the first year of life in $82 \%$.

CAL spots were obvious on naked eye examination in the majority of cases but in a few fair skinned subjects they were extremely pale. The only affected subjects aged below 20 years with fewer than six spots was a 17 year old male with five lesions and axillary freckling, but from the age of 20 years an increasing number of cases had fewer than six spots. In some, the spots may have become disguised by multiple neurofibromas but several older patients reported 'disappearance' of CAL spots.

Four cases were classified as equivocal (fig 1), CAL spots being the only finding on examination. Three subjects aged $0 \cdot 1,1 \cdot 8$, and $3 \cdot 5$ years had one, two, and one lesions respectively and one six year old had five extremely pale lesions $1 \mathrm{~cm}$ in diameter. Seven out of $50(14 \%)$ subjects aged over five years were classified as normal despite having one or two CAL spots.

Axillary freckling, the other form of characteristic skin pigmentation in NF-1, was present in 108 of 155 (70\%) affected subjects. It appeared later than the CAL spots, the youngest case with this feature being three years old.

CUTANEOUS NEUROFIBROMAS

The youngest subject with cutaneous neurofibromas was six years old. The proportion of cases with this feature increased from the age of 10 years; they were present in all affected subjects aged 17 years or over (table 2, fig 2). The number of cutaneous neurofibromas increased with age (table 2). These lesions were not seen in any at risk subjects classified as normal or equivocal.

The main problem caused by these lesions was cosmetic. However, in the majority of cases they were found on the trunk and were only present in large numbers on exposed areas of the body in more severe cases; in only 17 of 94 cases $(18 \%)$ in the Welsh population ${ }^{11}$ were there numerous lesions on the head and neck. 


\section{LISCH NODULES}

The age of appearance of Lisch nodules was between that of CAL spots and cutaneous neurofibromas (fig 2). The youngest child in whom they were seen was three years old, but the majority of children under five were unable to cooperate with examination. These lesions were seen in 104 of 122 $(85 \%)$ subjects overall and 71 of $76(93 \%)$ of those over 20 years old. Lisch nodules were not seen in at risk subjects without one or both of the other major features.

A subset $(n=53)$ of the Welsh population had domiciliary slit lamp findings confirmed on more detailed ophthalmological assessment at the University Hospital of Wales. The findings have been reported in detail elsewhere. ${ }^{13}$

\section{COMPLICATIONS}

Table 3 shows the number of major complications of NF-1 which had occurred/were present in the affected subjects identified in the population based study. The cases have been differentiated into four groups: index cases, affected relatives, all affected under 18 years old, and affected 18 years old or over.
Complications seen in the study population not listed in table 3 were delayed puberty $(2 \cdot 1 \%$ males $)$ and bony defect of the lambdoidal suture (1\%).

Complication frequencies for counselling purposes are presented in table 4 and fig 3 . Frequencies for adults (18 years or over) are used to compensate for the variable age at which complications develop. The only exception to this are the figures used for intellectual handicap where all subjects aged five years or over were used.

In fig 3 the age range at presentation and frequency of each of the major complications is shown. The age range during which a given feature may present has been derived as follows. From review of previously published series: aqueduct stenosis, ${ }^{14}$ endocrine tumours, ${ }^{15} 16$ CNS tumours (including optic gliomas), ${ }^{17} 18$ pseudoarthrosis, ${ }^{19}$ rhabdomyosarcoma, ${ }^{2021}$ and scoliosis ${ }^{22} 23$; from the age of presentation in this study and that of Riccardi and Eichner ${ }^{9}$ : plexiform neurofibromas; for intellectual handicap it was assumed that severe developmental delay would have been identified by the age of five years and milder problems by the end of primary school education; for the remaining compli-

TABLE 3 Frequency of NF-1 complications in 135 cases ascertained through the population based study in south east Wales.

\begin{tabular}{|c|c|c|c|c|}
\hline Complication & $\begin{array}{l}\text { No of index cases } \\
(n=83 \text { unless stated })\end{array}$ & $\begin{array}{l}\text { No of affected relatives } \\
(n=52 \text { unless stated })\end{array}$ & $\begin{array}{l}\text { No }(\%) \text { of all cases } \\
<18 \text { years of age } \\
(n=39 \text { unless stated })\end{array}$ & $\begin{array}{l}\text { No }(\%) \text { of all cases } \\
\geqslant 18 \text { years } \\
(n=96 \text { unless } \text { stated })\end{array}$ \\
\hline \multicolumn{5}{|l|}{ Plexiform neurofibromas } \\
\hline All lesions & $27 / 77$ & $13 / 48$ & $17 / 39(43 \cdot 6)$ & $23 / 86(26 \cdot 7)$ \\
\hline Large lesions of head and neck & 4/77 & $0 / 48$ & $3 / 39(7 \cdot 7)$ & $1 / 86(1 \cdot 2)$ \\
\hline \multicolumn{5}{|l|}{ Limb/trunk lesions associated with } \\
\hline significant bone/skin hypertrophy & $2 / 77$ & $4 / 48$ & $2 / 39(5 \cdot 1)$ & $4 / 86(4 \cdot 7)$ \\
\hline \multicolumn{5}{|l|}{ Education } \\
\hline Special school education & $9 / 73$ & $4 / 51$ & $1 / 34(2 \cdot 9)$ & $12 / 90(13 \cdot 3)$ \\
\hline Remedial class education & $14 / 73$ & $7 / 51$ & $8 / 34(23 \cdot 5)$ & $13 / 90(14.4)$ \\
\hline Normal education, specific learning difficulties & $5 / 73$ & $2 / 51$ & $2 / 34(5 \cdot 9)$ & $5 / 90(5 \cdot 6)$ \\
\hline \multicolumn{5}{|l|}{ Epilepsy } \\
\hline No known cause & 3 & 3 & $2(5 \cdot 1)$ & $4(4 \cdot 2)$ \\
\hline Secondary to disease complication & 2 & 1 & 0 & $3(3 \cdot 1)$ \\
\hline Hypsarrythmia* & 1 & 1 & $1(2 \cdot 6)$ & $1(1)$ \\
\hline CNS tumours & $2 \dagger$ & 0 & $2(5 \cdot 1)$ & $2-3 / 138(1 \cdot 5-2 \cdot 2 \%) \ddagger$ \\
\hline Spinal neurofibromas & 2 & 0 & 0 & $2(2 \cdot 1)$ \\
\hline Acoustic neuroma & 0 & 0 & 0 & 0 \\
\hline Aqueduct stenosis & 2 & 0 & 0 & $2(2 \cdot 1)$ \\
\hline Meningioangiomatosis & 1 & 0 & 0 & $1(1)$ \\
\hline Malignancy with established disease association & 0 & 0 & 0 & $4 / 138(2 \cdot 9) \ddagger$ \\
\hline \multicolumn{5}{|l|}{ Scoliosis } \\
\hline Requiring surgery & 5 & 1 & 1 & $5(5 \cdot 2)$ \\
\hline Less severe & 3 & 4 & $1(2 \cdot 6)$ & $6(6 \cdot 3)$ \\
\hline \multicolumn{5}{|l|}{ Pseudoarthrosis of tibia \pm fibula } \\
\hline \multicolumn{5}{|l|}{ Resulting in non-union and eventual below } \\
\hline knee amputation & 2 & 1 & $1(2 \cdot 6)$ & $2(2 \cdot 1)$ \\
\hline Less severe forms & 1 & 1 & $1(2 \cdot 6)$ & $1(1)$ \\
\hline Gastrointestinal neurofibromas & 3 & 0 & $1(2 \cdot 6)$ & $2(2 \cdot 1)$ \\
\hline Renal artery stenosis & 2 & 0 & 0 & $2(2 \cdot 1)$ \\
\hline Phaeochromocytoma & 1 & 0 & 0 & $1(1)$ \\
\hline Duodenal carcinoid & 2 & 0 & 0 & $2(2 \cdot 1)$ \\
\hline Congenital glaucoma & 1 & 0 & 0 & 1 (1) \\
\hline
\end{tabular}

*Occurred at 0.6 and 0.7 years, resolved with ACTH therapy.

†Both optic gliomas.

$\Varangle$ See text for explanation. 
TABLE 4 Frequency of complications for counselling purposes. The complications have been grouped according to their effects on a given person's lifestyle.

\begin{tabular}{ll}
\hline Complication group & Frequency $(\%)$ \\
\hline Intellectual handicap & \\
Moderate-severe retardation & $3 \cdot 2$ \\
Minimal retardation or learning difficulties & $29 \cdot 8$ \\
Total & $33 \cdot 0$ \\
& \\
Developing in childhood and causing lifelong morbidity & \\
Severe plexiform neurofibromas of head and neck & $1 \cdot 2$ \\
Scoliosis, requiring surgery & $5 \cdot 2$ \\
Severe pseudoarthrosis & $2 \cdot 1$ \\
Total & $8 \cdot 5$ \\
& \\
Treatable' complications which can develop at any age & \\
Aqueduct stenosis & $2 \cdot 1$ \\
Epilepsy & $4 \cdot 2$ \\
Spinal neurofibromas & $2 \cdot 1$ \\
Visceral neurofibromas & $2 \cdot 1$ \\
Endocrine tumours & $3 \cdot 1$ \\
Renal artery stenosis & $2 \cdot 1$ \\
Total & $15 \cdot 7$ \\
& \\
CNS and malignant tumours & \\
Optic gliomas & $0 \cdot 7$ \\
Other CNS tumours & $0 \cdot 7 \cdot 1 \cdot 5$ \\
Rhabdomyosarcoma & $1 \cdot 5$ \\
Peripheral nerve malignancy & $1 \cdot 5$ \\
Total & $4 \cdot 4-5 \cdot 2$ \\
\hline
\end{tabular}

cations given as having a 'lifelong' risk of presentation, examples of each occurring from childhood throughout life were found either in this series or in published reports. Insufficient data are available to provide a more accurate age range.

Complications occurred at random but showed apparent clustering in three families. In one, a mother and her two affected children had required special schooling (details of the father's schooling were not available); in a second family, two children required special schooling and one remedial class education (their parents and three normal sibs had attended normal school). In both families it was felt that social and environmental factors could partly have contributed to the children's school performance. In a third family the affected mother and a daughter had a gastrointestinal neurofibroma removed (but from different sites) and two other affected children (who lived outside the study area) had had surgery for spinal neurofibromas.

Clinical details of the complications are described elsewhere ${ }^{11}$; three are reported here in more detail to illustrate the derivation of figures used for counselling (fig 3, table 4). Variable presentation and outcome of treatment of certain complications is evident in the cases shown in figs 4 and 5 .

PLEXIFORM NEUROFIBROMAS

These lesions presented as large subcutaneous

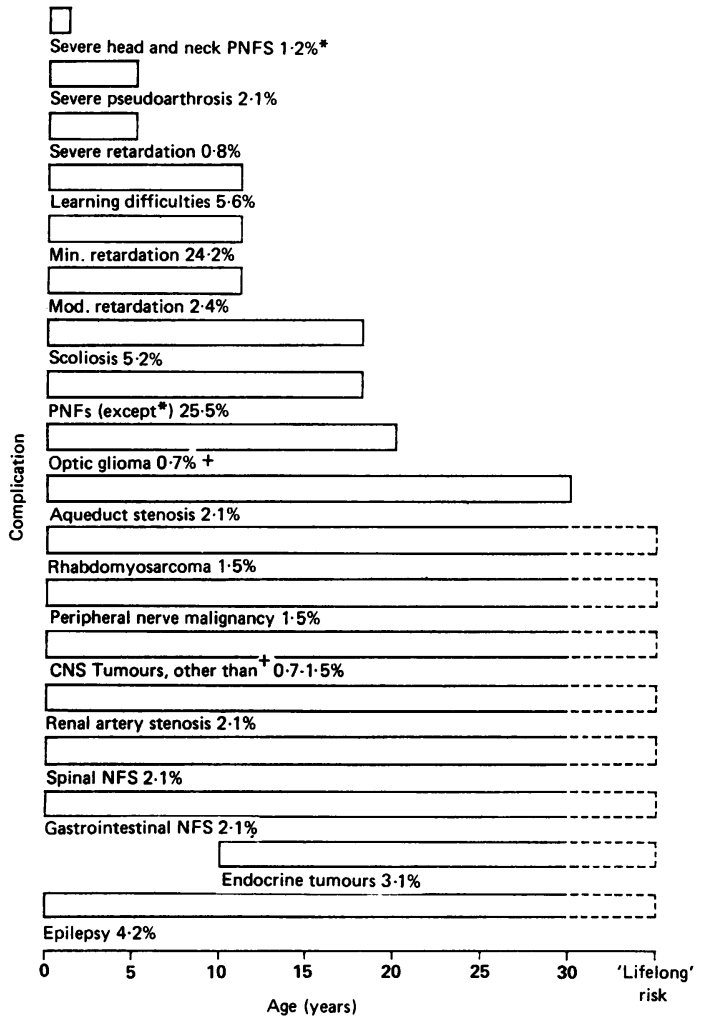

FIG 3 Age range of presentation and frequency of major NF-1 complications. The following abbreviations have been used: PNFS for plexiform neurofibromas and NFS for neurofibromas.

swellings with ill defined margins and a soft consistency, although occasionally hypertrophied nerve trunks could be palpated within the mass. The skin overlying the lesion was abnormal in 23 of 45 lesions (five subjects had two) owing to a combination of hypertrophy, CAL pigmentation, or hypertrichosis.

Although the lesions were asymptomatic their cosmetic burden was considerable; the frequency of the more severe lesions is presented in table 3. Large plexiform neurofibromas of the head and neck were present in four cases, in all of whom they were apparent soon after birth, and resulted in a series of corrective plastic surgical procedures. In three subjects the lesions arose from branches of the trigeminal nerve and in the fourth the lower branch of this nerve plus the nerves supplying the upper part of the neck were involved. A further group of six cases has been subdivided because of particularly large truncal lesions (two cases) associated with severe hypertrophy of the overlying skin (one of 


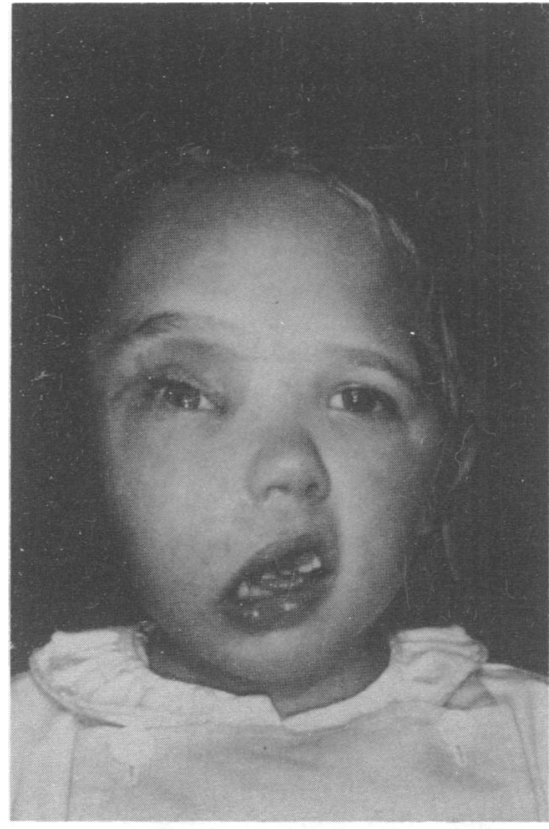

(a)

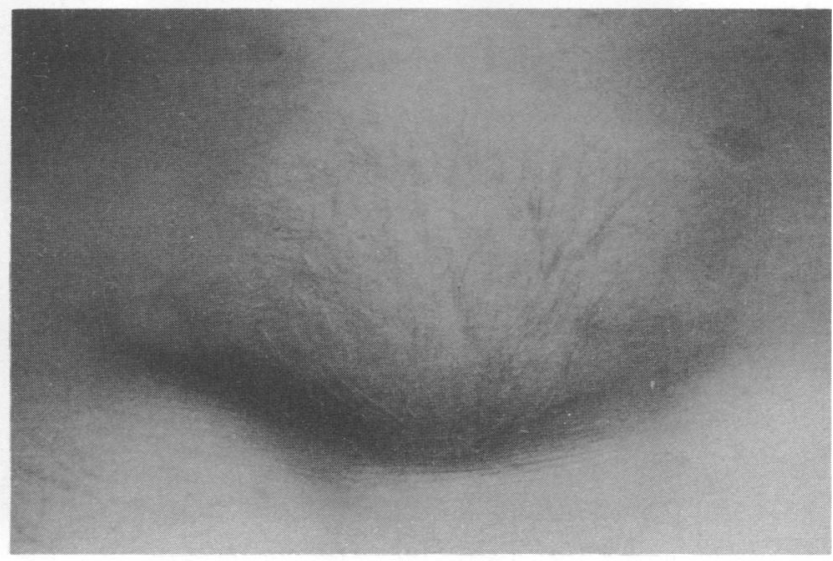

(b)

FIG 4 Plexiform neurofibromas. (a) Facial plexiform neurofibroma in a four year old girl who had presented at two months of age. She had already had a number of surgical procedures. (Reproduced with permission from Huson SM. Neurofibromatosis In: Swash M. Oxbury J, eds. Clinical neurology. Edinburgh: Churchill Livingstone (in press).) (b) Plexiform neurofibroma overlying lumbar spine of eight year old boy. The lesion was asymptomatic and had been noted on routine examination at three years of age. Lumbar spine $x$ rays were normal.

whom had had several surgical procedures) and large lesions affecting the lower limb (four cases). In three of these the lesions were around the ankle and overgrowth of the underlying bones had occurred.

\section{INTELLECTUAL HANDICAP}

This was assessed by comparing the educational experience of each affected subject with that of normal subjects with an affected parent. The outcome for affected subjects is shown in table 3 ; no normal sibs required special schooling and only two of $45(5 \%)$ remedial class education. In only two affected subjects were there NF-1 complications which might have accounted for these problems. In one case, who had attended a special school, hypsarrythmia might have caused the intellectual handicap and in another, who had attended a remedial class, hydrocephalus secondary to aqueduct stenosis might have been responsible.

Of the affected adults only one was severely retarded, having an intellectual age of two years when seen at 33 years. Of the 11 other adults who had attended a special school two were subjectively classified as moderately retarded as they could barely read or write and, although living in the community, required considerable family support. The remaining nine were classified as minimally retarded, since they were reasonably literate and leading independent lives. Those who required remedial class education were also classified as minimally retarded. Of the 34 children (aged from five to 18 years) only one was attending a special school and was moderately retarded (aged 13 years at assessment); eight were in remedial class education (classified as minimally retarded). Of the seven subjects who reported specific learning difficulties the main problem was or had been in reading, with normal performance in other areas.

The educational data on adults and children have been combined (table 4, fig 5) giving the following frequencies: severe retardation one of $124(0 \cdot 8 \%)$, moderate retardation three of $124(2 \cdot 4 \%)$, minimal retardation 30 of $124(24 \cdot 2 \%)$, and specific learning difficulties seven of $124(5 \cdot 6 \%)$. 


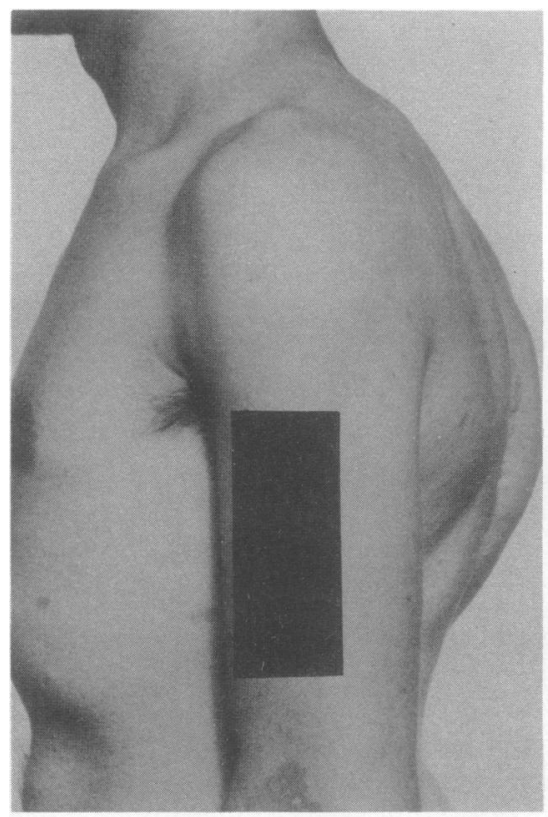

(a)

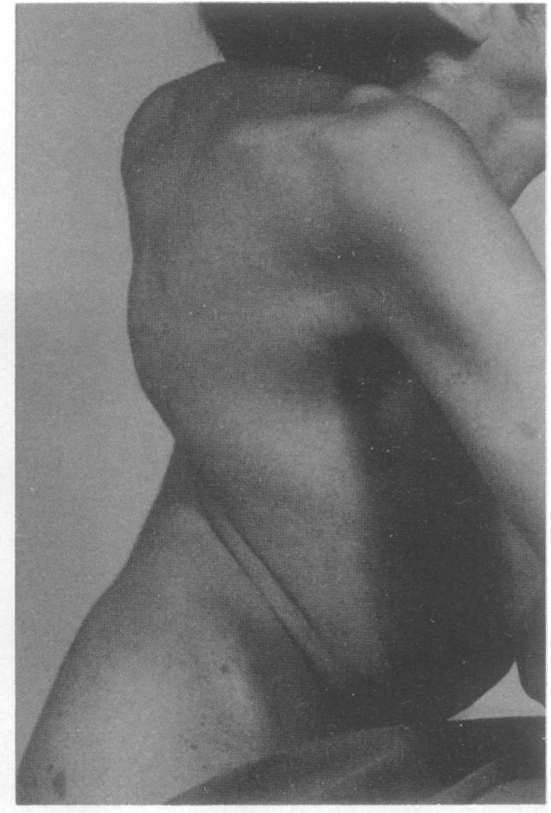

(b)

FIG 5 Scoliosis. (a) Corrected scoliosis in a 26 year old male with no underlying radiological vertebral abnormality on $x$ ray (curve T8 to T12, corrected from $95^{\circ}$ to $56^{\circ}$ ). No symptoms at time of assessment. (b) Kyphoscoliosis in a 19 year old male; the vertebrae involved were abnormal and although he had had a spinal fusion (aged 13 years) there is severe residual deformity.

CNS TUMOURS AND MALIGNANCY

Only two subjects in the study population had CNS tumours (both optic gliomas) and none had a malignancy related to NF-1. The frequency of tumours was derived from their occurrence in all affected subjects aged 18 years or over on the prevalence date (1 June 1985), whether residing in $(n=95)$ or outside $(n=18,12$ personally examined $)$ the study area and their dead affected relatives $(n=25)$.

One subject (aged 33 years), residing outside the study area, had undergone enucleation of the right eye and optic nerve at the age of three years. Two relatives had died as a result of astrocytomas; one affected case had a frontal lesion, and the other a cerebellar tumour although in this case the diagnosis of NF-1 was uncertain. The frequency of all CNS tumours is therefore two of $138(1.5 \%)$ if the latter case is excluded; the two optic gliomas (table 3) occurred in affected subjects aged under 18 years.

With respect to NF-1 related malignancy, two children had died from pelvic rhabdomyosarcomas (aged six months and two years), giving a frequency of two of $138(1 \cdot 5 \%)$. Two relatives had malignant tumours of peripheral nerves; one had died from a neurofibrosarcoma at 24 years and the other, who lived outside the study area and was not personally examined, had a low grade malignant neurilemmoma removed at 33 years, with no recurrence up to the time of the study (four years later). The frequency of peripheral nerve malignancy in this cohort is therefore two of $138(1.5 \%)$.

\section{Discussion}

Our experience in assessing offspring of subjects with NF-1 suggests that all those who have inherited the gene satisfy the diagnostic criterion of six or more CAL spots by the age of five years and that a large proportion do so by the age of one year. These findings are in agreement with those of Riccardi and Eichner. ${ }^{9}$ In the great majority of cases the distinction between normal and affected sibs was clear cut from an early age. The only exceptions were the four children aged six years or less who had between one and five CAL spots. Previous studies of the 
general population have shown that between 13.8 and $25 \cdot 3 \%{ }^{24}{ }^{25}$ have one to three CAL spots and it is therefore likely that three of these children (each with one or two lesions) are normal. Only one case, the six year old with five $1 \mathrm{~cm}$ diameter lesions and no other features, probably represented a truly 'equivocal' diagnosis. In assessing young children with six or more CAL spots and normal parents, a definite diagnostic label of NF-1, although likely, is not certain until other features develop, as families have been reported with multiple CAL spots alone segregating as an autosomal dominant trait. ${ }^{9}$

Lisch nodules were not included as diagnostic criteria in the present study as at the outset there had been only one previous report of their frequency in a large number of patients ${ }^{26}$ and no study had assessed their prevalence in the general population. During the course of this study two reports on the frequency of Lisch nodules in NF-1 were published. ${ }^{27}{ }^{28}$ There is now general agreement that Lisch nodules have a characteristic appearance, develop early in childhood, increase in number with age, and are present in over $90 \%$ of affected subjects by the age of five years. We also examined ${ }^{13}$ the irides of 150 normal subjects attending a general ophthalmology clinic and found one otherwise normal subject (aged 27 years) who had two lesions which were clinically indistinguishable from Lisch nodules. No other features of NF-1 were present in this patient or her parents, neither of whom had Lisch nodules. Since it is unlikely that the two Lisch nodules represent the sole manifestation of a NF-1 gene mutation, a more probable explanation is that normal persons occasionally have one or two lesions. Lisch nodules were included in the diagnostic criterion for NF-1 decided upon by the 1987 consensus conference on neurofibromatosis ${ }^{29}$; as they appear before cutaneous neurofibromas, their presence should help to resolve diagnostic difficulties presented by children with multiple CAL spots but no family history, those in whom the diagnosis is equivocal, and unusual cases.

The disease related morbidity and mortality in NF-1 is largely dictated by the occurrence of one or more of its complications. In presenting figures for counselling purposes (fig 5, table 4) we have not combined our data with those of previous studies as they are not directly comparable, either through failure to distinguish different forms of neurofibromatosis $^{4}{ }^{7}$ or ascertainment bias ${ }^{x-10}$ or both. ${ }^{6}$ Although we have analysed the frequency of complications in a geographically defined population with only NF-1, the frequency of complications may still represent an overestimate because of failure to ascertain mildly affected cases who had not sought medical opinion. One way to compensate for this would have been to analyse the frequency of complications in affected relatives, but our methodology must have identified most subjects with severe complications. Of those problems which would not necessarily have led to hospital referral (epilepsy, intellectual handicap, minor scoliosis, or plexiform neurofibromas) we found no significant difference in frequency between index cases and affected relatives. Four previously recognised complications of NF-1 (spenoid wing dysplasia, pseudoarthrosis of the radius or ulna or both, arterial disease other than renal artery stenosis, and atypical forms of childhood leukaemia) were not seen in the study population even though these are part of the disease spectrum. ${ }^{9}{ }^{30-32}$ It must be assumed that their occurrence is rare $(\leqslant 1 \%)$ in NF-1 sufferers.

The risk of intellectual handicap is often a major factor influencing reproductive decisions for a particular disorder. The frequency of intellectual handicap in NF-1 has been looked at in some detail in four previous series. Borberg, ${ }^{10}$ who ascertained cases through hospital records, found that the distribution of IQ was $<70$ (seven of $71,10 \%$ ); 70 to 80 (three of $71,4 \%) ; 80$ to 90 (45 of $71,63 \%$ ); and $>90$ (16 of $71,23 \%)$. Carey et al, ${ }^{6}$ ascertaining cases through genetic clinic records, found $11.4 \%$ of index cases and $4.2 \%$ of affected relatives had an IQ of $<70$; $11.4 \%$ of the remainder had learning difficulties. Samuelsson, ${ }^{7}$ in a population study with similar methodology to our own, found that two of 71 $(2 \cdot 8 \%)$ adult cases had required special school education and 30 of $71(42 \%)$ remedial class education. Riccardi and Eichner, ${ }^{9}$ studying cases referred to a special interest clinic, found that 18 of $201(9 \%)$ cases had an IQ of $<70$ and $30 \%$ of the whole population $(n=238)$ had learning difficulties. The present study confirms the high frequency of learning difficulties $(5 \cdot 6 \%)$ and minimal intellectual handicap $(24 \cdot 2 \%)$, but found a slightly lower frequency of moderate/severe handicap $(2.4 \%$ and $0.8 \%$ respectively) than most previous studies. A more exact understanding of the intellectual burden of NF-1 will only be reached when a large series of children are followed, with appropriate psychometric examinations, from early childhood.

\section{GENETIC COUNSELLING}

Only 10 of $135(7 \%)^{11}$ of the affected subjects in the population survey had received formal genetic counselling. Many were unaware that their particular complication was part of the disease complex and most thought of NF-1 merely as a 'skin complaint'. Those who had sought to inform themselves from lay medical publications had an exaggerated impression of their risk of malignancy or fear of becoming 'an elephant man'. ${ }^{33}$ Informing families about the 
varied complications of NF-1 is a difficult counselling task and there is a fine balance between providing adequate information and causing unnecessary alarm. In counselling families we have found it useful to divide the complications into the four groups shown in table 4 . This avoids the use of a long list of complications and focuses on the effect a given complication group will have on the person's life.

In fig 3 we have presented age ranges for presentation of the majority of NF-1 complications. It is intended that this can be used when seeing patients to assess what complications a person of a given age is still at risk of developing. This can be used both for reassurance, for example, a young adult with no problems to date can be reassured that they have no risk of certain complications, and in monitoring complications which may yet occur. We do not feel that any one complication, other than intellectual handicap, occurs frequently enough to warrant screening investigations, and regular clinical examinations should suffice, biannually for children with a preschool psychological assessment and annually for adults, unless a particular complication indicates more frequent review.

In reviewing the available data for age of presentation of complications it is clear that for several our knowledge of their natural history is limited. There is a need for long term prospective follow up of cohorts of NF-1 sufferers from childhood. Only then will uncertainties regarding the true frequency of complications and their natural history be resolved. Clinical features which predispose to the development of certain malignancies may emerge, thus identifying a subpopulation of NF-1 sufferers who require closer follow up.

We are grateful to the patients and their families, the British Neurofibromatosis Patients Association (LINK), the Wolfson Foundation, and Action Research for the Crippled Child for their support, Mrs L Beck and Mr D Jones for assistance with ophthalmological examinations, and Mrs S Kingsley for secretarial services.

\section{References}

' Barker V. Wright E. Nguyen K. et al. Gene for von Recklinghausen neurofibromatosis is in the pericentromeric region of chromosome 17. Science 1987:236:1100-2.

2 Scizinger BR. Roulcau GA. Ozclius LG, et al. Genetic linkage of von Recklinghausen neurofibromatosis to the nerve growth factor receptor genc. Cell 1987:49:589-94.

${ }^{3}$ Goldgar DE, Green P, Parry DM, Mulvihill JJ. Multipoint linkage analysis in neurofibromatosis type 1: an international collaboration. Am J Hum Genet 1989:44:6-12.

4 Crowe FW, Schull WJ, Neele JV. A clinical, pathological and genetic study of multiple neurofibromatosis. Springfield, Illinois: C C Thomas, 1956.

5 Huson SM, Compston DAS, Harper PS. A genetic study of von
Recklinghausen neurofibromatosis (NF-1) in south east Wales. 1 Prevalence, fitness, mutation rate, and effect of parental transmission on severity. J Med Genet 1989;26:704-11.

- Carey JC, Laub JM, Hall BD. Penetrance and variability of neurofibromatosis: a genetic study of 60 familics. Birth Defects 1979;15(5B):271-81.

7 Samuelsson B. Neurofibromatosis (von Recklinghausen's disease): a clinical-psychiatric and genetic study. MD thesis. University of Gothenburg, 1981.

* Brasfield RD, Das Gupta TK. Von Recklinghausen's disease: a clinicopathological study. Ann Surg 1972;175:86-104.

${ }^{9}$ Riccardi VM, Eichner JE Neurofibromatosis: phenotype, natural history and pathogenesis. Baltimore: Johns Hopkins University Press, 1986.

${ }^{10}$ Borberg A. Clinical and genetic investigations into tuberous sclerosis and Recklinghausen's neurofibromatosis. Acta Psychiatr Neurol Scand 1951;71(suppl II):1-239.

11 Huson SM, Harper PS, Compston DAS. Von Recklinghausen neurofibromatosis: a clinical and population study in South East Wales. Brain 1988;111:1355-81.

12 Huson SM, Meredith AL, Sarfarazi M, Shaw DJ, Compston DAS, Harper PS. Linkage analysis of peripheral neurofibromatosis (von Recklinghausen disease) and chromosome 19 markers linked to myotonic dystrophy. J Med Genet 1986;23: 55-7.

${ }^{13}$ Huson SM, Jones D, Beck L. Ophthalmic manifestations of von Recklinghausen neurofibromatosis. Br J Ophthalmol 1987;71: 235-8.

14 Horwich A, Riccardi VM, Francke U. Brief clinical report. Aqueductal stenosis leading to hydrocephalus-an unusual manifestation of neurofibromatosis. Am J Med Genet 1983;14: $577-81$.

is Modlin IM, Farndon JR, Shepherd A, et al. Phaeochromocytoma in 72 patients: clinical and diagnostic features, treatment and long term results. Br J Surg 1979;66:456-65.

16 Griffiths DFR, Williams GT, Williams ED. Duodenal carcinoid, phaeochromocytoma and neurofibromatosis: islet cell tumor, phaeochromocytoma and the von Hippel Lindau complex: two distinctive neuroendocrine syndromes. $Q J$ Med 1987;64: 769-82.

17 Illgren EB, Kinnier-Wilson LM, Stiller CA. Gliomas in neurofibromatosis: a series of $\mathbf{8 9}$ cases with evidence for enhanced malignancy in associated cerebellar astrocytomas. Pathol Annu 1985;20:331-58.

18 Lewis RA, Gerson LP, Axelson KA, Riccardi VM, Whitford RP. Von Recklinghausen neurofibromatosis. II. Incidence of optic glomata. Ophthalmology 1984;91:929-35.

${ }^{19}$ Morrissy RT, Riseborough EJ, Hall JE. Congenital pseudoarthrosis of the tibia. J Bone Joint Surg (Br) 1981;63:367-75.

20) Hartley AL, Birch JM, Marsden HB, Harris M, Blair V. Neurofibromatosis in children with soft tissue sarcoma. Pediatr Hematol Oncol 1988;5:7-16.

${ }^{21}$ Hope DG. Mulvihill JJ. Malignancy in neurofibromatosis. Adv Neurol 1981:29:33-5.

22 Chaglassian JH, Riseborough EJ, Hall JE. Neurofibromatosis scoliosis. Natural history and results of treatment in thirty-seven cases. J Bone Joint Surg (Am) 1976;56:695-702.

23 Winter RB. Moe JH, Bradford DS, Lonstein JE. Pedras CV, Weber AH. Spine deformity in neurofibromatosis. J Bone Joint Surg (Am) 1979;61:677-94.

24 Burwell RG, James NJ, Johnston DI. Café-au-lait spots in school children. Arch Dis Child 1982;57:631-2.

25 Kopf AW, Levine LJ, Rigel DS, Friedman RJ, Levenstein M. Prevalence of congenital nevus-like-nevi, nevi spilli, and café au lait spots. Arch Dermatol 1985:121:766-9.

26 Lewis RA. Riccardi VM. Von Recklinghausen neurofibromatosis. Incidence of iris hamartomata. Ophthalmology 1981; 88:348-54.

${ }^{27}$ Flueler U. Boltshauser E. Iris hamartomata as diagnostic criterion in neurofibromatosis. Neuropediatrics 1986;17:183-9. 
28 Zehavi C. Romano A. Goodman RM. Iris (Lisch) nodules in ncurofibromatosis. Clin Genet 1986:29:51-5.

29 Neurofibromatosis. NIH consensus development statement. Arch Neurol 1988:45:575-8.

30 Savino PJ, Glaser JS, Luxenburg MN. Pulsating enophthalmos and choroidal hamartomas: two rare stigmata of neurofibromatosis. Br J Ophthalmol 1977;61:483-8.

${ }^{31}$ Levisohn PM. Mikhael MA, Rothman SM. Cerebrovascular changes in neurofibromatosis. Dev Med Child Neurol 1978;20: $789-93$.
32 Bader JL, Miller RW. Neurofibromatosis and childhood leukemia. J Pediatr 1978:92:925-9.

33 Treves F. A case of congenital deformity. Trans Pathol Soc Lond 1885:36:494-8.

Correspondence to Dr S M Huson, Department of Medical Genetics, Churchill Hospital, Headington, Oxford OX3 7LJ. 